\title{
DISSERTAÇÕES E TESES COMO OBJETOS E FONTES DA ESCRITA COMPARADA SOBRE CURRÍCULO EM EDUCAÇÃO ESPECIAL (2004 a 2012)
}

Fabiany Tavares Silva(*) Laura Kethlyn Souza Duarte(*)

\section{NOTAS INTRODUTÓRIAS}

No Brasil, a Constituição Federal de 1988 garante a ampliação do acesso e a permanência à educação ao assegurá-la, sob o lema da "escola para todos", como um direito subjetivo fundamental e essencial de todos os brasileiros, independente da sua condição física, cognitiva, econômica e social, "o acesso ao ensino obrigatório e gratuito é direito público subjetivo" (art. 208, $\S 1^{\circ}$ ).

A década de 1990, marcada por discussões e mudanças educacionais que buscam favorecer o processo de inclusão escolar de uma parcela da população, anteriormente excluída deste espaço, significa a admissão de todos aqueles considerados diferentes, incluindo as pessoas com deficiência.

Desta forma, este processo culmina na aprovação de diversas legislações, entre elas a Lei de Diretrizes e Bases da Educação (LDB) 9.394/1996 e, no âmbito da Educação Especial as Diretrizes Nacionais para a Educação Especial na Educação Básica (2001), a Política Nacional de Educação Especial na perspectiva da Educação Inclusiva (2008), entre outras.

Particularmente, no cenário das discussões curriculares no âmbito da Educação Especial, além das diretrizes, acima mencionadas, publicam-se os Parâmetros Curriculares Nacionais (PCN) Adaptações Curriculares (MEC, 1999) e as Diretrizes Operacionais para o atendimento educacional especializado na Educação Básica, modalidade Educação Especial (2009). Tais documentos acabam por propor um novo modelo de escola, instituição agora responsável pela promoção da inclusão, considerando a incorporação em seus projetos "currículos, métodos, técnicas, recursos educativos e organização específicos” (art. 59, LDB 9.394/1996), bem como ofertar o atendimento educacional especializado, para atender as necessidades educacionais dos alunos com deficiência (art. 208, $\mathrm{CF} / 1988)$.

\footnotetext{
${ }^{(*)}$ Professora-pesquisadora da Universidade Federal de Mato Grosso do Sul (UFMS), atuando na Graduação e no Programa de Pós-graduação (Cursos de Mestrado e Doutorado), tendo como objetos de estudo e pesquisas os Estudos Comparados (Método), o currículo (políticas, documentos e práticas), a Escola e a cultura escolar.

${ }^{(* *)}$ Pedagoga formada pela Universidade Federal (UFMS) em 2016. Atualmente Professora de Ensino Fundamental.
} 
Todavia, como "cada escola possui um processo muito particular de lidar com o conjunto de normativas e, principalmente, de incorporar ou não essas exigências" (SILVA, 2006, p. 31), chegamos à segunda década do século XXI sem de fato possuir uma escola, que, realmente, seja inclusiva.

E ainda, não esquecemos que as escolas respondem as demandas do Estado, da família e da sociedade, incorporando as exigências de tais e (re)contextualizando-as na cultura escolar, ou seja, no seu "conjunto de práticas, normas, ideias e procedimentos que se expressam em modos de fazer e pensar o cotidiano da escola" (VIÑAO FRAGO, 2000 apud SILVA, 2006, p. 31).

Deste modo, é preciso considerar que "[...] responder às diferentes necessidades de cada aluno pode ser considerada uma nova cultura escolar" (MÔNACO, 2008, p. 47), sendo necessário repensar todas as práticas escolares, desde as curriculares às organizacionais e moralistas presentes no ambiente escolar, normalmente escondidas sob a máscara da igualdade individual e de oportunidades.

Alia-se a isso, que as políticas públicas brasileiras delineadas pela ótica neoliberal, em especial no que diz respeito aos financiamentos, depara-se com a abertura da escola inclusiva, sem desconsiderar o fato de que:

[...] o mesmo sistema político, cultural, educativo etc. que produz a exclusão não poderia ter a pretensão de instalar impunemente o argumento de um sistema radicalmente diferente - chame-se de integração, inclusão, ou como bem se deseje nomear. (SKILIAR, 2006, p. 28).

Nessa direção estamos centrados nos estudos curriculares para a investigação dos processos de inclusão e exclusão escolar, tendo por base o currículo como um território organizado por meio de normativas, de orientações, de interesses profissionais e de interesses de aprendizagem, na base dos pressupostos da globalidade da ação educativa, da diferenciação/flexibilidade curricular e da integração das atividades educativas.

No tocante à inclusão escolar, apreendida em um discurso que oferece novas alternativas para o desenvolvimento de relações sociais e escolares democráticas, que estabelece elos entre o político e o pedagógico, a fim de incentivar o aparecimento de “contraesferas públicas" 1" implicadas na transformação. E, a exclusão escolar, fundada em uma visão crítica das instituições de ensino, ao considerarmos que as experiências formadoras efetivamente vivenciadas na escola não se reduzem

\footnotetext{
${ }^{1}$ Pensar a dimensão do público implica atentar para um imperativo "descentramento" da teoria social que leve em conta as diversas formas pelas quais categorias sociológicas produzidas em determinados contextos são interpretadas e mobilizadas em outras realidades (CONNELL, 2007).
} 
ao programa oficial de aprendizagem, pois ao lado dos saberes explicitamente prescritos, a escola pode também transmitir valores e modelos culturais implícitos.

Quanto ao currículo ultrapassamos a mera prescrição de objetivos, conteúdos e métodos, entendendo que articula conflituosamente as tensões e relações de poder, ideais políticos, sociais, econômicos e culturais, por meio dos quais determinados conhecimentos são selecionados em detrimento de outros, assim como hábitos, valores e normas a serem transmitidos no ambiente escolar.

[...] o currículo não é um instrumento pedagógico neutro, ao contrário é um campo de conflitos, tensões e relações de poder, do qual resulta um conjunto de prescrições sobre os conteúdos, as organizações e as práticas, que reflete (e reproduz) as relações sociais e políticas existentes em cada momento histórico, que são negociadas, efetivadas, construídas e reconstruídas na escola. (SILVA, 2010, p. 219).

Diante disso, estamos ancorados em um dos conteúdos de pesquisa concluída ${ }^{2}$, precisamente aquele que visa analisar o conhecimento difundido sobre a relação currículo e educação especial, em dissertações e teses produzidas no período de 2004 a 2012, particularmente, orientadas pela/na construção de respostas às necessidades da construção de atuações curriculares dirigidas, facilitadoras da inclusão escolar das pessoas com deficiência.

Vale registrar, dissertações e teses não são tomadas como relatórios finais de um curso de pós-graduação, mas, como objetos e fontes de análise:

$\mathrm{Na}$ condição de objetos, entendidos como impressos, que selecionam, legitimam e distribuem conhecimentos, mobilizam discursos na produção das verdades sobre a relação estudada. Como fontes, particularmente escritas e dialógicas, ocupam de um lado, espaço privilegiado de reconstituição das ideologias ou mentalidades educativas subtraídas a uma projeção particular, oficial e; de outro se diferenciam de outras fontes, por contemplar propósito muito particularizado, isto é, o cumprimento de funções determinadas pela difusão e o desenvolvimento prático dos processos de análise da educação, a partir de uma rede de intertextualidades que se alimenta desde a política educativa ao desenvolvimento dos processos nas escolas e nas salas de aulas. (SILVA, 2016, p. 214).

Dessa forma, não exercitamos críticas sobre a qualidade destes relatórios, tampouco negamos a relevância que os discursos construídos nesses textos possuem, compreendendo os

\footnotetext{
${ }^{2}$ Pesquisa A Escrita Comparada do Processo de Distribuição de Conhecimentos por Documentos Curriculares (20002012), coordenada pela professora Fabiany de Cássia Tavares Silva, financiada na modalidade Bolsa Produtividade, CNPq.
} 
diálogos como produtos científicos, como atos políticos, pelo fortalecimento que apresentam para o campo da pesquisa em educação especial e, particularmente, em currículo.

Diante disso, o recorte temporal proposto corresponde ao período posterior a implantação das Diretrizes Nacionais para a Educação Especial na Educação Básica (2001), que deflagra a organização e implantação dos atendimentos educacionais especializados (AEE). Vale destacar, que apreendemos o AEE como espaço, que inaugura um novo marco legal, teórico e organizacional da/na educação pública brasileira, tendo como objetivos facilitar a articulação entre a escolarização comum e a especializada, possibilitando o desenvolvimento da aprendizagem e da convivência sem discriminação.

Para tanto, localizamos que a proposição deste espaço escolar, particularmente, na educação básica, não só assegura o desenvolvimento da aprendizagem, como, também, inaugura outro marco, a discussões/proposições de currículo em educação especial. Para compreender essa relação e as análises construídas, incorporadas e tornadas públicas, selecionamos dissertações e teses produzidas no período acima referido, nos Programas de Pós-graduação em Educação, distribuídos pelas diferentes regiões do Brasil.

Os procedimentos estão fundados no processo de levantamento, seleção e análise das produções acadêmicas acessadas na Biblioteca Digital de Dissertações e Teses (BDTD) da CAPES. $\mathrm{O}$ acesso a esta base de dados ancora-se em critérios de inclusão e exclusão, assim definidos: identificação apenas dos trabalhos, que objetivamente estudam as relações procuradas, restritos a educação básica, nas etapas da educação infantil, ensino fundamental e, na modalidade, de educação especial e; descarte dos trabalhos, que investigam o "ensino de", formação de professores, saberes docentes e, produções a partir de tratamentos dos conteúdos específicos, respectivamente.

Justificamos o uso da BDTD, por reunir, em um único portal de buscas, teses e dissertações defendidas em todo o território nacional e também, por brasileiros no exterior, permitindo o mapeamento e a identificação de produtos científicos de diferentes áreas do conhecimento e temáticas. No entanto, destacamos que as produções não se resumem ao acúmulo de dados, considerando os conteúdos necessários à escrita comparada.

Diante disso, elegemos alguns descritores para identificá-las, a saber: currículo, prática curricular, educação básica, Educação Especial, atendimento educacional especializado, inclusão escolar, escola inclusiva, adaptação curricular e acessibilidade curricular. Além da tarefa de identificação, os descritores operam, também, contribuindo para apreender as leituras produzidas, a fim de identificar as contribuições, as considerações dos autores, as continuidades e 
descontinuidades, semelhanças e diferenças, que explicitam determinações mais gerais, que regem a relação analisada.

Neste exercício identificamos $\mathbf{0 8}$ dissertações cruzando os descritores currículo/Educação Especial/inclusão escolar/escola inclusiva/atendimento educacional especializado/acessibilidade curricular e 02 teses com prática curricular, currículo e Educação Especial. A seguir, o quadro com as dissertações e as teses selecionadas:

Quadro 1. Dissertações e Teses.

\begin{tabular}{|c|c|c|c|}
\hline TIPO & AUTOR/TÍTULO & PALAVRAS CHAVES & NO \\
\hline Dissertação & $\begin{array}{l}\text { ANTUNES, R. A. Inclusão Escolar na Pré- } \\
\text { Escola: o acesso ao currículo. }\end{array}$ & $\begin{array}{l}\text { Currículo; Adaptação Curricular; } \\
\text { Inclusão Escolar; Deficiência } \\
\text { Intelectual; Pré-Escola. }\end{array}$ & 2008 \\
\hline Dissertação & $\begin{array}{l}\text { BARBOSA, M. C. Do preferencial ao } \\
\text { necessário: o atendimento educacional } \\
\text { especializado na escola comum. }\end{array}$ & $\begin{array}{l}\text { Atendimento Educacional } \\
\text { Especializado; Educação } \\
\text { Inclusiva; Educação Especial; } \\
\text { Diferenças. }\end{array}$ & 2012 \\
\hline Dissertação & $\begin{array}{l}\text { BUYTENDORP, A. A. B. M. Currículo em } \\
\text { Educação Especial: o texto, as imagens e o } \\
\text { acesso ao ensino. }\end{array}$ & $\begin{array}{l}\text { Currículo, Ensino, Educação } \\
\text { Especial. }\end{array}$ & 2006 \\
\hline Dissertação & $\begin{array}{l}\text { EFFGEN, A. P. S. Educação Especial e } \\
\text { currículo escolar: possibilidades nas práticas } \\
\text { pedagógicas. }\end{array}$ & $\begin{array}{l}\text { Currículo, Educação Especial, } \\
\text { Formação Continuada, Trabalho } \\
\text { Colaborativo, Práticas } \\
\text { Pedagógicas Inclusivas. }\end{array}$ & 2011 \\
\hline Dissertação & $\begin{array}{l}\text { LOBO, J. A. Projetos políticos-pedagógicos de } \\
\text { escolas da rede municipal de ensino de } \\
\text { Corumbá/MS. }\end{array}$ & $\begin{array}{l}\text { Educação Especial, Currículo e } \\
\text { Política Educacional; }\end{array}$ & 2011 \\
\hline Dissertação & $\begin{array}{l}\text { MELO, H. A. O acesso curricular para } \\
\text { alunos(as) com deficiência intelectual na rede } \\
\text { regular de ensino: a prática pedagógica na sala } \\
\text { de recursos como eixo para análise. }\end{array}$ & $\begin{array}{l}\text { Deficiência Intelectual, Sala de } \\
\text { Recursos, Acessibilidade } \\
\text { Curricular. }\end{array}$ & 2008 \\
\hline Dissertação & $\begin{array}{l}\text { MÔNACO, S. M. Da educação especial à } \\
\text { (re)invenção da escola para todos: exclusão, } \\
\text { inclusão escolar e educação inclusiva [1994- } \\
\text { 2008]. }\end{array}$ & $\begin{array}{l}\text { Escola para Todos; Inclusão } \\
\text { Escolar; Educação Especial; } \\
\text { Escolarização. }\end{array}$ & 2008 \\
\hline Dissertação & $\begin{array}{l}\text { XAVIER, G. do C. O currículo e a Educação } \\
\text { Inclusiva: a prática curricular e suas } \\
\text { implicações na inclusão escolar de alunos com } \\
\text { necessidades educacionais especiais. }\end{array}$ & $\begin{array}{l}\text { Currículo Escolar; Escola } \\
\text { Inclusiva; Necessidades } \\
\text { Educacionais Especiais. }\end{array}$ & 2008 \\
\hline Tese & $\begin{array}{l}\text { PLETSCH, M. D. Repensando a inclusão } \\
\text { escolar de pessoas com deficiência mental: } \\
\text { diretrizes políticas, currículo e práticas } \\
\text { pedagógicas. }\end{array}$ & $\begin{array}{l}\text { Deficiência Mental; Educação } \\
\text { Especial; Políticas de Inclusão } \\
\text { Escolar; Práticas Curriculares; } \\
\text { Etnografia. }\end{array}$ & 2009 \\
\hline Tese & $\begin{array}{l}\text { VIEIRA, A. B. Currículo em Educação } \\
\text { Especial: as ações da escola a partir dos } \\
\text { diálogos cotidianos. }\end{array}$ & $\begin{array}{l}\text { Educação Especial; Inclusão } \\
\text { Escolar; Currículo; Formação } \\
\text { Continuada. }\end{array}$ & 2012 \\
\hline
\end{tabular}

Fonte: BDTD. Autor: SILVA; DUARTE, 2016.

Vale destacar, de acordo com o gráfico abaixo, que a maior parte das produções selecionadas concentra-se em programas de Pós-Graduação da região sudeste do país e, nota-se a ausência de produções nas regiões sul e norte. Além disso, destacamos o Programa de PósGraduação em Educação da Universidade Federal de Mato Grosso do Sul, tendo em vista que as dissertações selecionadas da região centro-oeste são todas oriundas dele. 


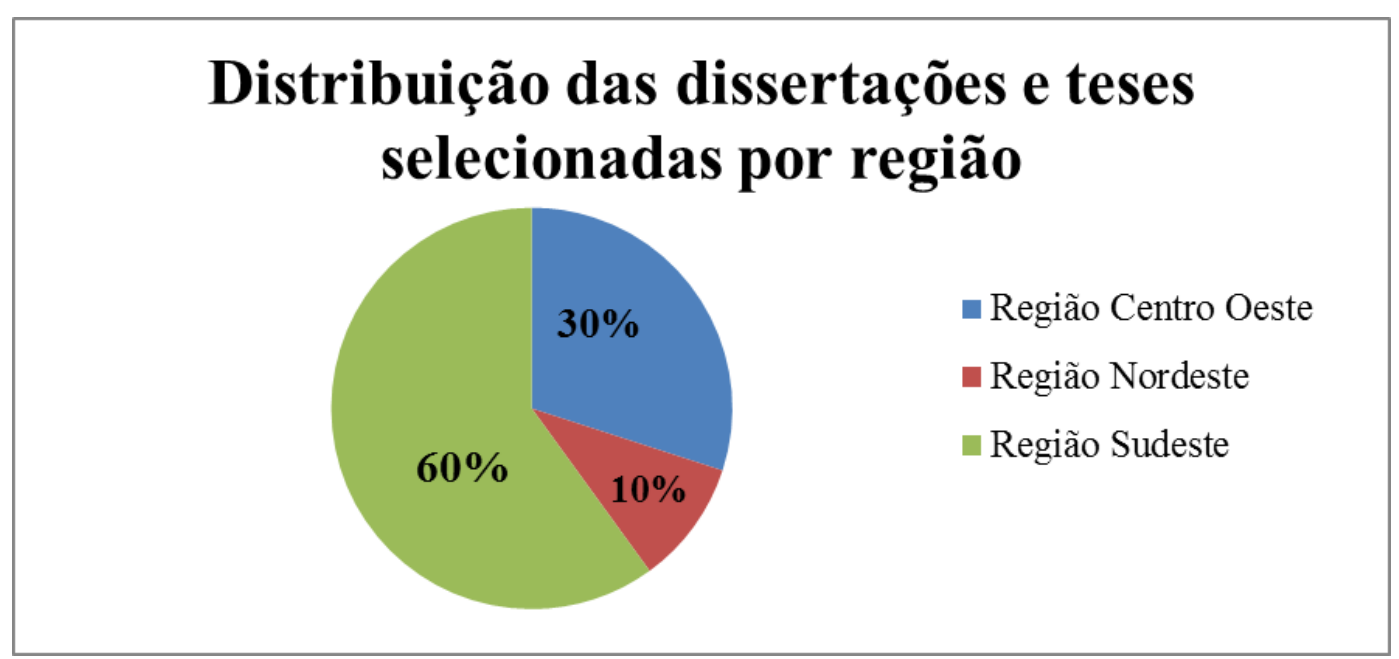

Fonte: DUARTE; SILVA, 2017.

Acrescemos que as análises que construímos utilizaram uma versão do estudo comparado, que de acordo com Silva (2017):

[...] recorre à educação comparada, tomando-a como resultante de um duplo movimento, de um lado, marcado por uma presença crescente das questões educativas na criação de identidades escolares, definidas não tanto numa perspectiva geográfica, mas no sentido de uma pertença a certas comunidades discursivas. De outro, deslocando-a da referência tradicional interpaíses para dimensões simultaneamente intra e extra nacionais, isto é, centradas nas comunidades de referência dos agentes locais e, nos processos de regulação, nos âmbitos nacional e internacional (p. 5).

Dito de outro modo, uma nova epistemologia do conhecimento, de cunho sócio histórico, que define perspectivas de pesquisa centradas não apenas na materialidade dos fatos educativos, mas também sobre os mercados simbólicos que os descrevem, interpretam e localizam em um dado espaço-tempo (POPKEWITZ, 1998).

A par disso, a proposição de uma escrita comparada se alimenta da procura por uma linguagem que liga, vincula, estrutura a experiência objetiva da comparação, a partir do cruzamento proposto, isto é, educação, história da educação e ciências sociais em comparação. Dessa forma compreendida como enfrentamento de análises, que se colocam intencionalmente contrárias a noção de método e ao ordenamento sistemático da exposição. Ancorada na premissa de registrar a produção da significação no funcionamento dos discursos e, neste caso, identificando neles, mais facilmente, a natureza social da linguagem comparada. 
Dessa forma, fundada nos discursos de outros, como forma material exterior do elemento semântico-ideológico interior, na construção do equilíbrio na comparação. Diante disso, temos a proposição de identificar e analisar como as dissertações e teses eleitas operam, nos limites deste artigo, entre uma razão sociológica e uma razão pedagógica, ambas legítimas e sem dúvida necessárias, mas certamente irredutíveis uma à outra, estando portanto condenadas a coexistir num campo plural e em permanente conflito, isto é, a necessidade da escolarização dos sujeitos com deficiência na escola regular e aproximá-los dos processos de aprendizagem assegurados por um currículo da educação básica.

\section{CURRÍCULO EM EDUCAÇÃO ESPECIAL: APROXIMAÇÕES À ESCRITA COMPARADA}

Com a abertura da "escola para todos", na década de 1990, observa-se uma mudança de paradigma no cenário educacional, a inclusão começa então a tomar forma, disseminando a ideia de uma escola aberta para toda e qualquer diferença anteriormente excluída deste espaço, o que impõe consequentemente novas formas de pensar o currículo e as suas diferenciações.

Neste contexto, o Ministério da Educação (MEC) publica em 1998 os Parâmetros Curriculares Nacionais (PCN), definindo os conteúdos básicos a serem ministrados nas instituições educacionais de todo o país e na sequência, em 1999, com o intuito de responder/atender as particularidades das pessoas com deficiência a Secretaria de Educação Especial (SEESp) do MEC lança os PCN - Adaptações Curriculares.

O PCN - Adaptações Curriculares busca garantir o direito de todos à educação e ao acesso ao conhecimento, reafirmando a proposta da escola inclusiva para as pessoas com deficiência ${ }^{3}$, ao sinalizar respostas às necessidades pedagógicas deste alunado, por meio das adaptações/ adequações/flexibilizações curriculares que orientam para uma diversificação das atividades, materiais e tempo de execução, partindo sempre de um currículo comum, agora passível de mudanças para otimizar o aprendizado dessas pessoas.

As adaptações curriculares constituem, pois, possibilidades educacionais de atuar frente às dificuldades de aprendizagem dos alunos. Pressupõem que se realize a adaptação do currículo regular, quando necessário, para torna-lo apropriado às

\footnotetext{
${ }^{3}$ Nos limites deste estudo, debruçamo-nos sobre as discussões de currículo em Educação Especial e consequentemente a escolarização das pessoas com deficiência. Embora o PCN - Adaptações curriculares (1999) utilize o termo necessidades educacionais especiais, que abarca não somente as pessoas com deficiência, nos referimos somente à estas pessoas, por serem o foco desta pesquisa e o público alvo da Educação Especial, de acordo com a Política Nacional de Educação Especial na perspectiva de Educação Inclusiva (2008).
} 
peculiaridades dos alunos com necessidades especiais. Não um novo currículo, mas um currículo dinâmico, alterável, passível de ampliação, para que atenda realmente a todos os educandos. [...] As adaptações curriculares apoiam-se nesses pressupostos para atender às necessidades educacionais especiais dos alunos, objetivando estabelecer uma relação harmônica entre essas necessidades e a programação curricular. Estão focalizadas, portanto, na interação entre as necessidades do educando e as respostas educacionais a serem propiciadas. (BRASIL, 1999, p. 33-34).

O alinhamento das políticas educacionais com a ótica neoliberal teve grande peso/impacto na implementação da inclusão escolar, atreladas de um lado, à promoção da qualidade, da competitividade, da valorização dos sujeitos em processo de formação escolar e; de outro, pautadas no maior equilíbrio e eficiência nos processos de ensino aprendizagem, ancorados na lógica da sociedade do capital, a qual preconiza:

[...] que todos podem vender a sua força de trabalho, inclusive os deficientes. Todos são iguais (guardadas as devidas especificidades) e estão disponíveis no mercado, como vendedores de força de trabalho e como consumidores. A proposta de inclusão é a resposta que a escola contemporânea assume nesse contexto. Outro dado significativo é a relação custo-benefício. Educar esses indivíduos com deficiência tem um custo menor para o governo do que mantê-los assegurados pelo resto da vida. (LOBO, 2011, p. 91).

Diante disso,

[...] uma reforma baseada em padrões de desempenho não está a preparar os alunos nem para a economia baseada no conhecimento, nem para o carácter e para o sentido de comunidade que estão para além dela (HARGREAVES 2003, p. 131).

Neste contexto, à educação especial, também reformada pelo discurso da inclusão escolar, tem adotado "diferentes concepções de ensino, aprendizagem e de currículo, e uma especialização nas diferenças peculiares dos alunos com necessidades especiais”. (BUYTENDORP, 2006, p. 35).

O ensino e a aprendizagem dos alunos com deficiência trazem à pauta os recursos, os meios e os materiais, tomados como instrumentos essenciais para facilitar o desenvolvimento do processo educativo nas aulas, acompanhados, na maioria das vezes de concepções psicológicas, como por exemplo, o construtivismo e, de uma especialização, representada pelos professores da Educação Especial, considerados, muitas vezes, os únicos capazes de lidar com esse público.

Acresce-se a esse contexto a construção de currículos diferenciados, colocados em um cenário no qual "o currículo flexível e a adaptação curricular passam a ser as palavras de ordem para o acesso à escolarização dos grupos excluídos” (LOBO, 2011, p. 95). Para tanto, tal adaptação 
deve partir de um currículo comum, caso o contrário poderá contribuir com o aumento da segregação e servir de controle, pois:

Ao ofertar acesso a determinados conhecimentos aos alunos ditos "normais" e suprimir a participação dos estudantes com deficiência, TGD e altas habilidades/superdotação a lógicas de socialização, esse ato demonstra alguns atravessamentos presentes nos currículos escolares, ou seja, o aluno é alguém menos capaz ou em condições inferiores de aprendizagem, não tendo, portanto, condições de entender o que é ensinado. (EFFGEN, 2011, p. 57).

Por isso, um currículo adaptado ligado às experiências, interesses ou mesmo o laudo desses alunos, acaba por sinalizar uma faceta reducionista da educação, ao restringir e limitar o processo educativo através de uma seleção de conhecimentos, considerado apropriado a uns e não a todos.

As referências de inclusão ainda estão muito acorrentadas ao sentido da deficiência, faltando ainda a transposição do sentido da inclusão para as diversas diferenças que se manifestam na escola, inclusive as abordadas no debate no campo do currículo. (XAVIER, 2008, p. 60).

Como afirmação das minorias, percebe-se que o sentido de deficiência passa a fazer parte dos discursos curriculares e das escolas inclusivas, mas o fato de que "[...] a educação inclusiva não acaba quando se coloca o aluno deficiente na escola comum" (MÔNACO, 2008, p. 72), transparece que “[...] são necessárias modificações não só nas políticas educacionais, como também nas práticas escolares obscurecidas e sedimentadas na homogeneidade entre os alunos" (MÔNACO, 2008, p. 17).

Tal fato provoca uma tensão na real função da escola, a transmissão do conhecimento poderoso $^{4}$, tendo em vista que o acesso e a permanência já não são mais o problema, mas sim, a aprendizagem do aluno com deficiência, pois “[...] se antes a exclusão era gerada pela falta de acesso à escola e pelas múltiplas reprovações, agora ela se funda sobre o aprendizado ou pelo aprendizado insuficiente, o que mostra a fragilidade da educação brasileira”. (PLETSCH, 2009, p. 52-53).

\footnotetext{
${ }^{4}$ Este conceito, conhecimento poderoso, é aqui entendido a partir das contribuições de Michael Young e refere-se ao conhecimento especializado adquirido no ambiente escolar, aquele que não pode ser adquirido no cotidiano (2007, p. 1294-1295).
} 
Neste cenário o atendimento educacional especializado 5 (AEE) é percebido "[...] como uma das possibilidades de acesso ao currículo, quando efetivada de fato nos ambientes escolares" (EFFGEN, 2011, p. 51). Este atendimento é marcado por recursos pedagógicos e metodologias educacionais específicas com o intuito de oferecer "ao aluno condições para transpor barreiras que encontra na sala de aula comum" (BARBOSA, 2012, p. 103) devendo "ser oferecido como complemento, não em substituição a esse”. (MÔNACO, 2008, p. 62).

Tal marca coloca em relevo os "nexos possíveis" dos discursos sobre o currículo em educação especial, qual seja:

[...] pensar a possibilidade de construção de um currículo comum que atenda aos diferentes percursos de aprendizagem dos alunos, procurando diversificar as práticas pedagógicas e tensionar as adaptações curriculares, a flexibilidade curricular e as adequações curriculares, que, muitas vezes, se apresentam como um esvaziamento de conteúdo na escolarização dos alunos com algum tipo de deficiência, TGD e altas habilidades/superdotação. (EFFGEN, 2011, p. 67).

No entanto, a adoção e a identificação dos recursos pedagógicos e das metodologias específicas no ambiente escolar ocorrem em função das identidades sociais e das deficiências e não das aprendizagens dos sujeitos, como deveria, ou seja, o laudo determina as possibilidades e impossibilidades daquele aluno a priori, sendo desconsiderado todo o seu processo próprio e o direito de aprendizagem.

[...] é preciso que haja muita reflexão para que a concretização de adaptações curriculares não crie um ambiente segregado, no qual o aluno para quem tais adaptações foram pensadas não fique à margem do currículo de referencia trabalhado com o grupo. (ANTUNES, 2008, p. 71).

$\mathrm{Na}$ tentativa de entender essa "negligência", percebe-se que “[...] o currículo [...] deve ser um dos recursos por meio dos quais possam ser garantidos o desenvolvimento e a aprendizagem de todos os alunos" (ANTUNES, 2008, p. 49), sendo, portanto, necessário adaptá-lo para atender a dificuldade destes alunos, mas sem perder de vista que a escola é o espaço responsável pela distribuição do conhecimento historicamente construído pela humanidade, assim como é um local que desenvolve um conhecimento próprio e que ambas as funções devem ser propiciadas a todos os alunos, sem qualquer distinção.

\footnotetext{
${ }^{5}$ A classificação desses alunos, para efeito de prioridade no atendimento (preferencialmente na rede regular de ensino), define-se pelas deficiências mental, visual, auditiva, física e múltipla; condutas típicas (problemas de conduta) e altas habilidades.
} 
Não há muitas opções além de pensarmos na construção de uma escola para todos, em que os conteúdos sejam pensados com um propósito consciente e consistente, em que a inclusão seja concebida no sentido mais amplo - e não apenas para as pessoas público-alvo da educação especial. (BARBOSA, 2012, p. 50).

Neste sentido, reconhecer a dimensão cultural indissociável do processo educativo é urgente, sendo necessário que a escola reflita “[...] que a diferença é parte constitutiva do humano e que a aprendizagem e a produção do conhecimento se efetivam quando reconhecemos a potência dos outros". (VIEIRA, 2012, p. 286).

Além disso,

[...] o acesso da pessoa com deficiência intelectual às atividades e conteúdos propostos pelo currículo, subtende a apropriação docente de conhecimentos que possam facilitar a avaliação de possíveis entraves para o ensino-aprendizagem, principalmente desses(as) alunos(as). (MELLO, 2008, p. 89).

$\mathrm{O}$ professor ao possuir conhecimentos que o ajude a problematizar e adaptar/adequar/flexibilizar o currículo, está mais próximo da efetivação do processo de aprendizagem dos alunos com deficiência e, neste sentido, pode construir ações articuladas com os demais profissionais da instituição escolar, permitindo que "[...] o ensino e a aprendizagem dos alunos deixa de ser incumbência desse ou daquele educador, e são considerados de responsabilidade de toda a escola que, coletivamente, reorganiza os recursos, os espaços e os profissionais de que dispõe". (VIEIRA, 2012, p. 302).

Diante disso, apreendemos a recorrência aos procedimentos/práticas pedagógicas no ambiente per se curricular, uma vez que estas representam ações que não envolvem:

[...] a elaboração e a implementação do currículo em suas diferentes dimensões (planejamento, metodologias, estratégias de ensino, avaliação, tempo e espaço de aprendizagem), as quais, por sua vez, são vinculadas ao processo histórico cultural dos sujeitos partícipes. (PLETSCH, 2009, p. 130).

Acresce-se a isso, que não é suficiente reconhecer o papel ideológico dessa recorrência, mas, torna-se necessário, também, observar como as representações acerca do currículo são construídas, assumidas, ensinadas, aprendidas, mediadas e apropriadas no contexto de formações discursivas e institucionais particulares de poder. E, nessas formações as

[...] práticas curriculares são desenvolvidas de forma coletiva e não individualizada pelos diferentes sujeitos presentes na instituição escolar, especialmente professores e alunos, considerando as contradições, tensões, conflitos, inovações e mudanças que figuram no espaço escolar. (PLETSCH, 2009, p. 130). 
Por fim, o direito a educação, inalienável e inquestionável, no caso dos alunos com deficiência, não pode ser simplificado ou minimizado, sendo necessário que todo o ambiente escolar empenhe-se em efetivar o processo de inclusão deste público, o que tenciona a cultura escolar, de modo que ela seja repensada, problematizada e reinventada.

E, o repensar, problematizar e reinventar torna-se um processo que distingue dois grandes discursos situados nos extremos, a saber: um fechado, composto de conteúdos claramente delimitados, separados e definidos sobre as condições de escolarização dos alunos com deficiência, apresentando diferenças consideráveis na prática pedagógica, nas formas de avaliação e de interpretação da inclusão; outro integrado, formado por conteúdos dispostos abertamente, submetidos a uma concepção capaz de ativar a construção de uma inclusão por baixo, por oposição à inclusão por cima, condutoras à uma prática pedagógica comum e a um mesmo estilo de avaliação. Contudo, não afastam a possibilidade de níveis intermediários de integração discursiva.

\section{SOBRE O CURRÍCULO EM EDUCAÇÃO ESPECIAL EM SENTIDO COMPARADO (OU NOTAS FINAIS)}

Consideramos que as produções identificadas e utilizadas (dissertações e teses) alimentam a escrita comparada, de um lado, por representar relações de forças internas e externas na busca da reflexão, problematização e questionamento sobre o currículo em educação especial; de outro, porque essa busca toma forma na tarefa de forjar lealdades educativas com a inclusão e a escola inclusiva.

Assim, ainda que no interior de determinada tradição discursiva, incorrem pelo enfrentamento das condições escolares das deficiências, acabando por determinar e corroborar outros discursos, isto é, dos requerimentos por adaptações/adequações/flexibilizações curriculares.

Neste contexto, a comparação nos apresenta a necessidade de aprimoramento dos debates em torno do currículo e da educação especial. Necessidade essa, que nos remete à noção de questionamento crítico, isto é, estimular “[...] a capacidade e a disposição a submeter questões e instituições políticas à análise crítica” (MCCOWAN, 2006, p. 140).

Noção essa, que longe de propor métodos específicos de ensino para a sala de aula, pauta-se na proposição das discussões sobre a diferenciação curricular ${ }^{6}$, uma vez que coloca em curso dois movimentos influentes, o pensamento crítico e a pedagogia crítica.

\footnotetext{
${ }^{6}$ Conceito que representa, essencialmente, mudanças na metodologia e na avaliação, pressupondo que os alunos têm um mesmo percurso nas suas opções, mas que uns precisam de seguir caminhos diferentes para que todos possam atingir o sucesso educativo (PACHECO, 2008, p. 182).
} 
O primeiro enfatiza o desenvolvimento da racionalidade e da capacidade de avaliar argumentos, identificar suposições, formular linhas de raciocínio, e assim por diante [...] A segunda, parte da premissa de que há certas injustiças fundamentais na sociedade e a educação é fator-chave para a sua perpetração e continuidade. Essas injustiças não parecem originar-se da falta de racionalidade dos indivíduos, mas sim de estruturas e práticas de opressão de alguns segmentos da sociedade sobre outros (MCCOWAN, 2006, p. 143).

A par disso, a comparação ressalta e atualiza um ponto de partida para pensar o currículo em educação especial, a adoção de novos conceitos (entre eles o da inclusão escolar) e o exame dos procedimentos/práticas de ensino, que indicam a existência a cristalização da falta de capacidade racional dos indivíduos com deficiência, historicamente assentada na condição da deficiência. Isto porque os ajustes curriculares necessários, ou as adaptações/adequações/flexibilizações, de alguma forma, circunscrevem-se a consideração da escolarização limitada a inculcar crenças e hábitos, contribuindo direta e continuamente para a reprodução e legitimação de valores discriminatórios (que revela a dificuldade da individuação, por implicar em não reflexão e não experimentação em relação aos seus objetos alvo) em contraposição ao currículo comum como instrumento da igualdade escolar, aproximado da sua necessária ultrapassagem, fundada no questionamento crítico.

Por fim, apreendemos evidentes conexões entre o objetivo educacional das dissertações e teses em promover o questionamento crítico das discussões/proposições de currículo em educação especial, e o objetivo pessoal, pautado em um forte compromisso com princípios de justiça, inaugurados pela proposição da escola inclusiva. Contudo, tais conexões acabam por não validar as informações essenciais para confrontar as concepções 'minimalistas' de currículo e educação especial. E, diante disso, lidar com o problema específico dessas concepções, por exemplo, a avaliação da complexidade e da natureza contestada da tradição curricular, como um modelo imposto externamente, até sua condição de prática de distribuição de conhecimentos. 


\section{REFERÊNCIAS}

ANTUNES, R. A. Inclusão Escolar na Pré-Escola: o acesso ao currículo. 2008. 165p. Dissertação (Mestrado em Educação) Universidade de São Paulo, São Paulo.

BARBOSA, M. C. Do preferencial ao necessário: o atendimento educacional especializado na escola comum. 2012. 179p. Dissertação (Mestrado em Educação) - Universidade Estadual de Campinas, Campinas.

BRASIL. Conselho Nacional de Educação. Secretaria de Educação Especial. Diretrizes Nacionais para a Educação Especial na Educação Básica. Resolução CNE/CEB no 2, de 11 de setembro de 2001. Brasília/DF: CNE/CEB, 2001. Disponível em: <http://portal.mec.gov.br/cne/arquivos/pdf/CEB0201.pdf〉. Acesso em: 20 set. 2018.

Constituição Federal (1988). Constituição da República Federativa do Brasil. Brasília/DF: 2012.

Secretaria de Educação Especial. Política Nacional de Educação Especial na Perspectiva da Educação Inclusiva. Brasília/DF: SEESP, 2008. Disponível em: 〈http://portal.mec.gov.br/arquivos/pdf/politicaeducespecial.pdf〉. Acesso em: 20 set. 2018.

Secretaria de Educação Fundamental/Secretaria de Educação Especial. Parâmetros Curriculares Nacionais: adaptações curriculares (estratégias para a educação de alunos com necessidades especiais). Brasília/DF: MEC, 1999. Disponível em: <http://200.156.28.7/Nucleus/media/common/Downloads_PCN.PDF>. Acesso em: 20 set. 2018.

BRASIL. Lei 9.394, de 20 de dezembro de 1996. Estabelece as diretrizes e bases da educação nacional. Diário Oficial da União. Brasília: Poder Legislativo, 23 dez. 1996, sec. I, n. 248, p. 27.83.. Disponível em: <http://www.planalto. gov.br/ccivil_03/leis/L9394.htm. Acesso em: 20 set. 2018.

BUENO, J.G.S. As políticas de inclusão escolar: uma prerrogativa da educação especial? In: BUENO, J G.S; MENDES, G.M.L; SANTOS, R.A. (Prgs.). Deficiência e escolarização: novas perspectivas de análise. Araraquara/SP: Junqueira \& Marin; Brasília/DF: CAPES, 2008. p. 43-63.

BUYTENDORP, A.A.B.M. Currículo em Educação Especial: o texto, as imagens e o acesso ao ensino. 2006. 108p. Dissertação (Mestrado em Educação) - Universidade Federal de mato Grosso do Sul, Campo Grande.

CONNELL, R. Southern Theory: The global dynamics of knowledge in social sciences. Cambridge (UK): Polity Press, 2007.

CRAHAY, M. Como a escola pode ser mais justa e mais eficaz? São Paulo: Cadernos Cenpec, 2013, p. 9-40.

EFFGEN, A. P. S. Educação Especial e currículo escolar: possibilidades nas práticas pedagógicas. 2011. 227p. Dissertação (Mestrado em Educação) - Universidade Federal do Espírito Santo, Vitória.

LOBO, J.A. Projetos políticos-pedagógicos de escolas da rede municipal de ensino de Corumbá/MS: aproximações às proposições de flexibilização/adaptações curriculares. 2011. 117p. Dissertação (Mestrado em Educação) - Universidade Federal de Mato Grosso do Sul, Campo Grande.

McCOWAN, Tristan. OS FUNDAMENTOS DO QUESTIONAMENTO CRÍTICO NA EDUCAÇÃO PARA A CIDADANIA. Currículo sem Fronteiras, v.6, n.2, pp.140-155, Jul/Dez 2006

MELO, H. A. O acesso curricular para alunos(as) com deficiência intelectual na rede regular de ensino: a prática pedagógica na sala de recursos como eixo para análise. 2008. 159p. Dissertação (Mestrado em Educação) - Universidade Federal do Maranhão, São Luís.

MÔNACO, S. M. Da educação especial à (re)invenção da escola para todos: exclusão, inclusão escolar e educação inclusiva [1994-2008]. 2008. 107p. Dissertação (Mestrado em Educação) - Universidade Federal de Mato Grosso do Sul, Campo Grande.

PACHECO, J. A. Para a noção de transformação curricular. Cadernos de Pesquisa, n. 159, vol. 46, p. 64-77, jan./mar. 2016.

notas sobre diversificação/diferenciação curricular em Portugal. InterMeio: Revista do Programa de Pós-Graduação em Educação, Campo Grande, MS, v. 14, n. 28, p. 178-187, jul.-dez. 2008.

PLETSCH, M. D. Repensando a inclusão escolar de pessoas com deficiência mental: diretrizes políticas, currículo e práticas pedagógicas. 2009. 256p. Tese (Doutorado em Educação) - Universidade Estadual do Rio de Janeiro, Rio de Janeiro.

SILVA, F.C.T. Estudos comparados como método de pesquisa: a escrita de uma história curricular por documentos curriculares. Revista Brasileira de Educação, vol. 21, n. 64, p. 209-224, jan./mar. 2016.

SKLIAR, C. A inclusão que é "nossa" e a diferença que é do "outro". In: RODRIGUES, David. (Org). Inclusão e educação: doze olhares sobre a educação inclusiva. São Paulo: Summus, 2006. p. 15-34.

VIEIRA, A. B. Currículo em Educação Especial: as ações da escola a partir dos diálogos cotidianos. 2012. 326p. Tese (Doutorado em Educação) - Universidade Federal do Espírito Santo, Vitória.

XAVIER, G. do C. O currículo e a Educação Inclusiva: a prática curricular e suas implicações na inclusão escolar de alunos com necessidades educacionais especiais. 2008. 197p. Dissertação (Mestrado em Educação) - Pontifícia Universidade Católica de Minas Gerais, Belo Horizonte. 


\section{RESUMO}

Este texto toma 8 dissertações e 2 teses, produzidas nos Programas de Pós-graduação em Educação no período de 2004 a 2012, como objetos e fontes para construir uma escrita comparada sobre as discussões/proposições de currículo para a modalidade Educação Especial. Consideramos que as produções identificadas e utilizadas (dissertações e teses) alimentam a escrita comparada, de um lado, por representar relações de forças internas e externas na busca da reflexão, problematização e questionamento sobre o currículo em educação especial; de outro, porque essa busca toma forma na tarefa de forjar lealdades educativas com a inclusão e a escola inclusiva.

Palavras-chave: Escrita Comparada. Educação Especial. Currículo. Dissertações e Teses.

\section{DISSERTATIONS AND THESES AS OBJECTS AND SOURCES OF THE COMPARATIVE WRITING ON CURRICULUM IN SPECIAL EDUCATION (2004 TO 2012)}

\section{ABSTRACT}

This text takes 8 dissertations and 2 theses, produced in the Graduate Programs in Education from 2004 to 2012, as objects and sources to construct a comparative writing about the discussions / propositions of curriculum for the Special Education modality. We consider that the productions identified and used (dissertations and theses) feed comparative writing, on the one hand, to represent relations of internal and external forces in the search for reflection, problematization and questioning about the curriculum in special education; on the other, because this search takes shape in the task of forging educational loyalties with inclusion and inclusive schooling.

Keywords: Comparative Writing. Special Education. Curriculum. Dissertations and Theses.

\section{DISERTACIONES Y TESIS COMO OBJETOS Y FUENTES DE LA ESCRITURA COMPARADA SOBRE EL CURRÍCULO EN EDUCACIÓN ESPECIAL (2004-2012)}

\section{RESUMEN}

Este texto incluye 8 disertaciones y 2 tesis, producidas en los Programas de Posgrado en Educación de 2004 a 2012, como objetos y fuentes para construir una escritura comparativa Consideramos que las producciones identificadas y utilizadas (disertaciones y tesis) alimentan la escritura comparativa, por un lado, para representar las relaciones de fuerzas internas y externas en la búsqueda de la reflexión, la problematización y el cuestionamiento del currículo en educación especial; por el otro, porque esta búsqueda se concreta en la tarea de forjar lealtades educativas con inclusión y escolarización inclusiva.

Palabras-clave: Escritura comparada. Educación especial. Currículo. Disertaciones y Tesis. 